\title{
Performance Analysis of High-temperature Two-stage Compression Heat Pump with Vapor Injection Dynamic Control
}

\author{
Win-Jet Luo, ${ }^{*}$ Jin-Chang Lai, ${ }^{1}$ Ming-Chu Hsieh, ${ }^{2}$ and I-Hsing Huang ${ }^{3}$ \\ ${ }^{1}$ Graduate Institute of Precision Manufacturing Engineering, National Chin-Yi University of Technology, \\ No. 57, Sec. 2, Zhongshan Rd., Taichung 41170, Taiwan \\ ${ }^{2}$ Department of Mechanical Engineering, National Chin-Yi University of Technology, \\ No. 57, Sec. 2, Zhongshan Rd., Taichung 41170, Taiwan \\ ${ }^{3}$ Department of Refrigeration, Air Conditioning and Energy Engineering, \\ National Chin-Yi University of Technology, No. 57, Sec. 2, Zhongshan Rd., Taichung 41170, Taiwan
}

(Received July 27, 2020; accepted December 1, 2020)

Keywords: heat pump, vapor injection, two-stage compression, heating performance

We proposed a vapor injection dynamic control method for a two-stage compression heat pump system with a circulating water heating method in order to attain high operational performance with increasing condensation temperature of the heat pump. During the water heating process, the circulating water is heated from a normal temperature of $35^{\circ} \mathrm{C}$ to a high temperature of $80^{\circ} \mathrm{C}$ and the corresponding condensation temperature of the refrigeration cycle is also increased from 40 to $85{ }^{\circ} \mathrm{C}$. Owing to the dynamical increases in the circulating water temperature and condensation temperature of the refrigeration cycle, the automatic and optimal control of the heat pump system in operation cannot be implemented through the traditional feedback control method by directly sensing the vapor injection pressure of the refrigeration cycle. It is found that, for optimal performance of the developed system in dynamical operation, the vapor injection pressure of the heat pump under each condensation temperature is related to the corresponding subcooling degree. The subcooling degree of the refrigeration cycle was obtained from the temperature sensors in the condenser and at the refrigerant inlet of the expansion valve. In this study, regarding the optimal performance operation of the heat pump system, a regression model of the subcooling degree in terms of different condensation temperatures of the refrigeration cycle was built in order to control the vapor injection pressure with the dynamic variations of the condensation temperature of the refrigeration cycle. By sensing the condensation temperature of the refrigeration cycle, the corresponding subcooling degree of the refrigeration cycle for the optimal vapor injection pressure can be determined from the regression model. Finally, the openness of the control valve on the vapor injection piping route was automatically adjusted to approach the corresponding optimal subcooling degrees of different condensation temperatures to attain high operational performance. The experimental results are in agreement with the theoretical results within the range of $10-20 \%$. In comparison with the system with constant vapor injection pressure, the coefficent of heating perfromance $\left(\mathrm{COP}_{h}\right)$ of the system can be increased by $20 \%$ with the vapor injection pressure

*Corresponding author: e-mail: wjluo@ncut.edu.tw

https://doi.org/10.18494/SAM.2020.3107 
control. From the experimental results, it is found that $\mathrm{COP}_{h}$ and the required power of the heat pump system using the proposed automatic control method are in reasonable agreement with those obtained by the optimal adjustment at different condensation temperatures. This indicates that the proposed model of automatic vapor injection can be applied to dynamically control the intermediate pressure of the refrigeration cycle to maintain high operational performance of a two-stage compression heat pump.

\section{Introduction}

The energy consumption of buildings for space heating and hot water accounts for about $40 \%$ of global energy consumption. Industrial power consumption accounts for $60 \%$ of the annual power consumption in Taiwan, in which the generation of a high-temperature heat source also accounts for most of the energy consumption. In this context, research on cleanprocess technology for sustainable development is particularly urgent. ${ }^{(1-3)}$ At present, the main heating methods are heating with a fuel as a heat source, electric heating, and heating by a heat pump. The principle of a heat pump is similar to that of a refrigeration system. The heat is moved from the low-temperature side to the high-temperature side through a refrigeration cycle, which is driven by an electric compressor. For the heat pump, the dissipation heat from the condenser is recovered for space heating or hot water generation. The heat pump has the advantages of little pollution, easy control, and high heating efficiency, and is considered to be a preferable heating method for space heating and sanitary water generation. ${ }^{(4)}$

However, for the applications of the heat pump in industry, high-temperature water in the temperature range from 60 to $90{ }^{\circ} \mathrm{C}$ is sometimes necessary in dehumidification processes, food processing, and water preheating for a steam boiler. Because of the high compression ratio in the compression process of the high-temperature heat pump, a two-stage compression heat pump system with an economizer is sometimes employed to improve the operational efficiency of the system.

Vapor injection technology has been applied to the two-stage compression system to reduce the operational temperature of the compressor, increase the subcooling degree of the refrigeration cycle, and further enhance the performance of the system. ${ }^{(4)}$ Regarding the development of vapor injection technology in the literature, Wang et al. ${ }^{(5)}$ investigated the effect of the vapor injection pressure on the performance of a multistage compression system. To reduce energy use, they suggested that the compression ratio of both compression stages should be the same for a two-stage compression system. Jiang et al. ${ }^{(6)}$ reported that a system with vapor injection can be effectively operated at low and high ambient temperatures. Baek et al. ${ }^{(7)}$ developed a two-stage compression heat pump model and found that, by employing a suitable vapor injection method, the coefficient of cooling performance $\left(C O P_{c}\right)$ and the coefficient of heating performance $\left(C O P_{h}\right)$ of the heat pump system were enhanced by 23.4 and $15.4 \%$, respectively. Qiao et al. ${ }^{(8)}$ experimentally investigated the performance of a $\mathrm{CO}_{2}$ heat pump at different condensation temperatures. They found that $\mathrm{COP}_{c}$ and $\mathrm{COP}_{h}$ of the $\mathrm{CO}_{2}$ heat pump were increased by 7.6 and $13.7 \%$, respectively, by vapor injection in comparison with those without vapor injection. Jin et al. ${ }^{(9)}$ designed a two-stage compression heat pump with a flash 
intercooler for vapor injection and experimentally investigated its performance at different ambient temperatures. They found that when the ambient temperature was $-20{ }^{\circ} \mathrm{C}$, the heating capacity and $\mathrm{COP}_{h}$ were $4.71 \mathrm{~kW}$ and 1.76 , respectively, and the discharge temperature of the second compression stage was less than $100{ }^{\circ} \mathrm{C}$. Redón et al. ${ }^{(10)}$ analyzed the performance of a two-stage vapor injection heat pump system with the refrigerants R-407c, R-22, R-290, and R32 under different operational conditions. They found that the seasonal $\mathrm{COP}_{h}$ of the vapor injection two-stage heat system with a flash tank was 30\% greater than that of a singleheat-pump system. The performance of vapor injection compression is affected by four main factors: the vapor injection pressure, the mass flow rate of the vapor injection, the superheating degree of the vapor injection, and the temperature of the refrigerant at the inlet of the expansion valve. Adjustment of the vapor injection can enable a system to operate under an optimal condition and attain high performance and a low discharge temperature from the compressor. In recent years, vapor injection technology has been applied in high-temperature heat pump systems to further enhance their performance. He et al. ${ }^{(11)}$ installed a vapor injection efficiency enhancer at the outlet of a condenser, which increased the vapor injection pressure from 0.82 to $0.98 \mathrm{MPa}$, the vapor injection flow ratio from 7.3 to $22.61 \%$, and the heating capacity by $7 \%$. Lee et al. ${ }^{(12)}$ discovered that $C O P_{h}$ of a heat pump with vapor injection gradually decreases with increasing compression ratio under a high compression ratio. Oquendo et al. ${ }^{(13)}$ compared the performance of vapor injection refrigeration systems with a vapor injection scroll compressor and a vapor injection two-stage reciprocating compressor. They found that if the compression rate of the compressor is lower than 7.5, the compression efficiency and volume efficiency of the vapor injection scroll compressor are higher than those of the vapor injection reciprocating compressor. Jung et al. ${ }^{(14)}$ investigated the heating performance of a heat pump with vapor injection in an electronic vehicle. They discovered that the isentropic efficiency and performance of the heat pump can be greatly improved by increasing the angle of vapor injection. At the ambient temperature of $-10{ }^{\circ} \mathrm{C}$, the heating performance of the heat pump was improved by 7.5 and $9.8 \%$, and the isentropic efficiency of the compressor was increased by 11.2 and $22.9 \%$ with the use of a single vapor injection port and two vapor injection ports, respectively, in comparison with the system without vapor injection.

For a two-stage heat pump with a flash tank for vapor injection, the liquid refrigerant altitude within the tank is often affected by the refrigerant pressure during the defrosting process; thus, vapor injection control has been examined recently. Xu et al. ${ }^{(15)}$ applied several vapor injection control methods to a heat pump with a flash tank. They found that when the liquid refrigerant altitude was maintained at $40-60 \%$ of the tank by sensing the refrigerant liquid level in the flash tank, the amount of refrigerant vapor injection attained a maximum value. Xu et al. ${ }^{(16)}$ developed a new vapor injection control model for a heat pump with a flash tank, in which a proportional-integral-differential (PID) controller was applied to control the openness of an electric expansion valve (EEV) at the high-pressure stage, a thermal expansion valve (TXV) was adopted at the low-pressure stage, and a thermal sensor was installed at the vapor injection port. A signal from the liquid level sensor in the flash tank was transmitted to the EEV and TVX to control the openness of the expansion valves and further control the liquid refrigerant altitude in the flash tank. Roh and $\mathrm{Kim}^{(17)}$ investigated a two-stage compression 
cycle with a variable-speed compressor. They found that the performance of a variable-speed two-step compression system was greatly affected by the control strategy of vapor injection, and the heating capacity and performance of the system could be enhanced by vapor injection. Jiang et al. ${ }^{(18)}$ investigated the effect of the vapor injection pressure on the performance of a two-stage heat pump system with a flash intercooler. They theoretically showed that increasing the vapor injection pressure increases the amount of vapor injection and the subcooling degree of the refrigeration cycle and enhances the performance of the system. Luo and coworkers ${ }^{(19,20)}$ developed an intelligent strategy for controlling the subcooling degree by sensing the condensation temperature and subcooled refrigerant temperature at the inlet of the expansion valve to dynamically obtain high performance of a heat pump at different condensation temperatures.

For a high-temperature heat pump system employing a circulating water heating method, the condensation temperature dynamically increases with increasing circulating water temperature. In past studies, regarding the vapor injection control for a two-stage compression heat pump system, the vapor injection control strategy usually assumed steady-state operational conditions, which sometimes cannot adapt to the dynamical operations of a heat pump system with circulating water heating. In this study, a model for controlling vapor injection pressure is proposed, which dynamically adapts to the operations of the heat pump system with circulating water heating. By sensing the condensation temperature of the refrigeration cycle, the corresponding subcooling degree of the refrigeration cycle for the optimal vapor injection pressure can be determined from a developed regression model. Finally, the openness of the control valve on the vapor injection piping route is adjusted automatically to approach the corresponding optimal subcooling degrees of different condensation temperatures by a controller. By the method for controlling vapor injection pressure, high operational performance of the system can be dynamically maintained.

\section{Configuration of Two-stage Compression Heat Pump and Experimental Methods}

\subsection{Configuration and specifications of two-stage compression heat pump system}

Figure 1 illustrates the configuration of the vapor injection two-stage compression heat pump system with a flash tank in this study. In the refrigeration cycle, high-pressure and hightemperature superheated refrigerant vapor is discharged from the two-stage compressor, then enters the refrigerant oil separator to separate the oil from the refrigerant. The separated oil is cooled after passing through an oil recovery unit and returns to the compressor for lubrication. The high-pressure and high-temperature superheated refrigerant vapor after the oil separator condenses into liquid refrigerant inside the condenser, and the condensation heat is recovered by water circulation to generate hot water. The condensed liquid refrigerant at the outlet of the compressor enters a subcooled state as it passes through the expansion valve to reduce the pressure, and flows into the flash tank. After the flash tank, two refrigerant piping circuits connect the flash tank and the compressor, i.e., a primary circuit and auxiliary circuit. The 


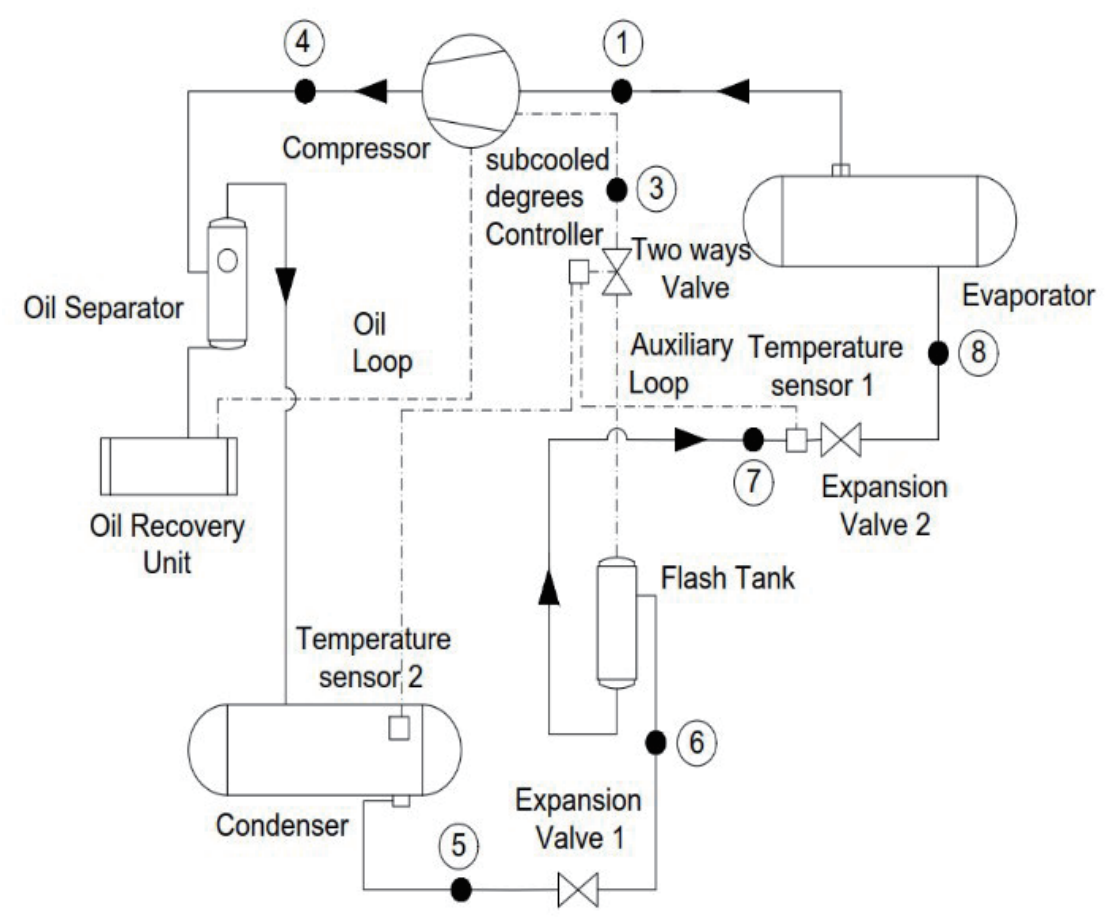

Fig. 1. Configuration of vapor injection two-stage compression heat pump system with flash tank.

pressure and temperature of the saturated liquid refrigerant at the bottom of the flash tank become low as it passes through the expansion valve along the primary circuit, then it flows into a flooded-type evaporator to absorb the heat from the evaporating circulating chilled water. The evaporated refrigerant vapor at the outlet of the evaporator becomes superheated vapor and flows into the compressor to proceed to the first stage of compression. The saturated refrigerant vapor at the top of the flash tank flows into the compressor after passing through a control value, then mixes with the superheated compressed vapor from the first compression stage. With the mixing of the two refrigerant vapor streams, the temperature of the compressed superheated vapor is reduced and the compression efficiency at the second stage of compression is also enhanced. The mixed refrigerant vapor proceeds to the second stage of compression, then it becomes a high-pressure and high-temperature superheated vapor, completing the refrigeration cycle. The control value on the secondary circuit can be used to control the vapor injection flow rate to the compressor. If the control valve is fully closed, the refrigerant cycle becomes a pure two-stage compression cycle without a vapor injection effect.

The specifications of the two-stage compression heat pump system with a flash tank are as follows:

1. Compressor: Semi-hermetic screw compressor with power consumption of $190 \mathrm{hp}$ and power supply of $380 \mathrm{~V}$.

2. Chiller: Flooded-type chiller with cooling capacity of $246.2 \mathrm{~kW}$ (70 RT).

3. Condenser with capacity of $363 \mathrm{~kW}(103.2 \mathrm{RT})$. 
4. Flooded-type oil cooler. In this study, the traditional two-tube oil cooler was replaced with a four-tube oil cooler, which can not only cool the oil but also reclaim heat.

5. Intercooler using a flash tank.

6. Oil separator: $120 \mathrm{~L}$; length, $1510 \mathrm{~mm}$; diameter, $500 \mathrm{~mm}$ (Kuen Ling Machinery Refrigerating Co., Ltd.)

\subsection{Vapor injection control method}

To maintain the high operational performance of the developed heat pump system in long-term operation and under different operational conditions, it is necessary to develop an automatic control program for the heat pump to adapt to condensation temperature variations.

In Fig. 1, the vapor injection control of the heat pump system in this study is illustrated. Four temperature sensors are installed at the outlet of the flash tank, the condenser, the suction line, and the evaporator in order to obtain the subcooling and superheating degrees of the refrigeration cycle in operation. The signals detected by the four temperature sensors are transmitted to a programmable logic controller (PLC) to calculate the corresponding subcooling and superheating degrees. The calculated parameters are inputted to the mathematical control model to obtain the corresponding intermediate pressure and also control the openness of the two-way valve in the vapor injection circuit. By the automatic control of vapor injection, the openness of the two-way valve can be adjusted to approach optimal operational performance at different condensation temperatures.

From temperature sensor 1, the temperature of the subcooled liquid refrigerant at the inlet of expansion valve 2 as in Fig. 1 can be detected. From temperature sensor 2, the condensation temperature of the refrigeration cycle can be detected. The temperature of the subcooled liquid refrigerant is subtracted from the condensation temperature to obtain the corresponding subcooling degree of the refrigerant cycle.

Similarly, from temperature sensors 3 and 4, the suction temperature of the compressor and the evaporation temperature of the refrigeration cycle are respectively obtained. The degree of superheating of the refrigeration cycle is obtained by calculating the difference between these two temperatures. The temperature signals from the sensors are transmitted to the PLC controller to control the openness of electronic expansion valve 2 in order to maintain a constant degree of superheating of the refrigeration cycle in operation.

\subsection{Theoretical analysis of the two-stage compression refrigeration cycle}

In the study, we analyze the performance of a high-temperature two-stage heat pump system with a flash tank intercooler for vapor injection, which is designed to have a constant evaporation temperature of $3{ }^{\circ} \mathrm{C}$, with the condensation temperature gradually increased from 50 to $85{ }^{\circ} \mathrm{C}$ by increasing the circulating water temperature. R134a refrigerant is used and the degree of superheating in the refrigeration cycle is controlled at $3{ }^{\circ} \mathrm{C}$. To improve the operational performance of the heat pump system and guarantee the injection of saturated vapor into the compressor, a flash tank intercooler is applied to the two-stage high-temperature 
heat pump. The corresponding theoretical $T-S$ (temperature-entropy) and $\log P-h$ (pressureenthalpy) diagrams are respectively illustrated in Figs. 2 and 3, which show the thermodynamic state points and operational pressures in the refrigeration cycle. In the theoretical analysis of the operational performance of the heat pump system, the following assumptions are made.

1. The thermodynamic states in the refrigeration cycle are in a semi-steady condition.

2. The drops in the refrigerant pressure in the condenser, evaporator, flash tank, and refrigerant piping are neglected.

3. The refrigerant vapor compression processes in the two-stage compressor are isentropic.

4. The refrigerant expansion processes in the expansion valves are isenthalpic.

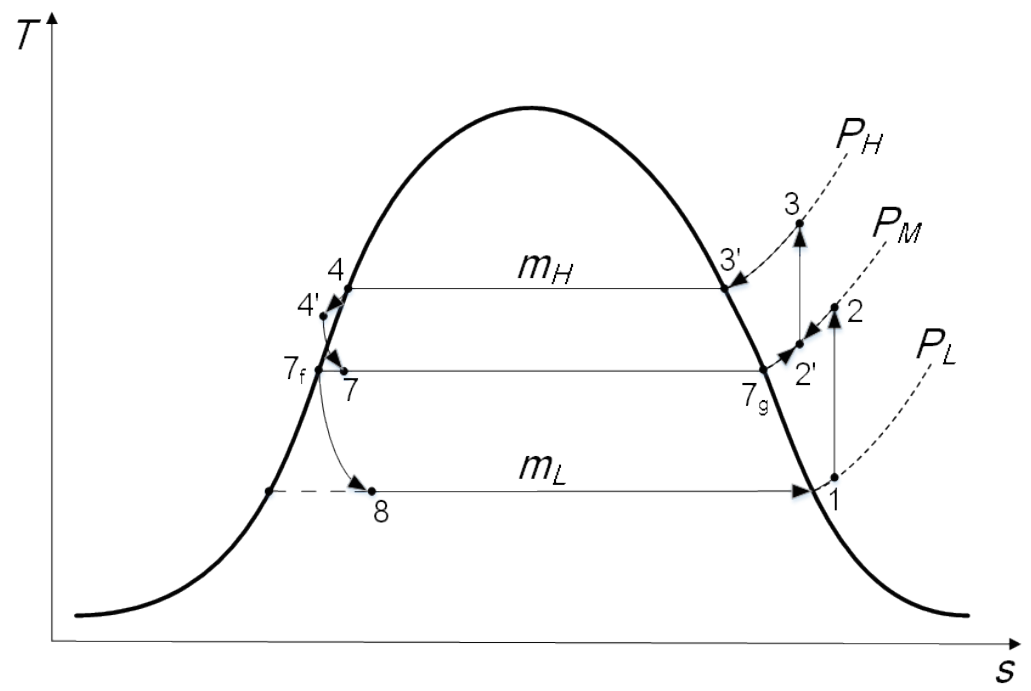

Fig. 2. Temperature-entropy diagram of the two-stage compression refrigeration with a flash tank.

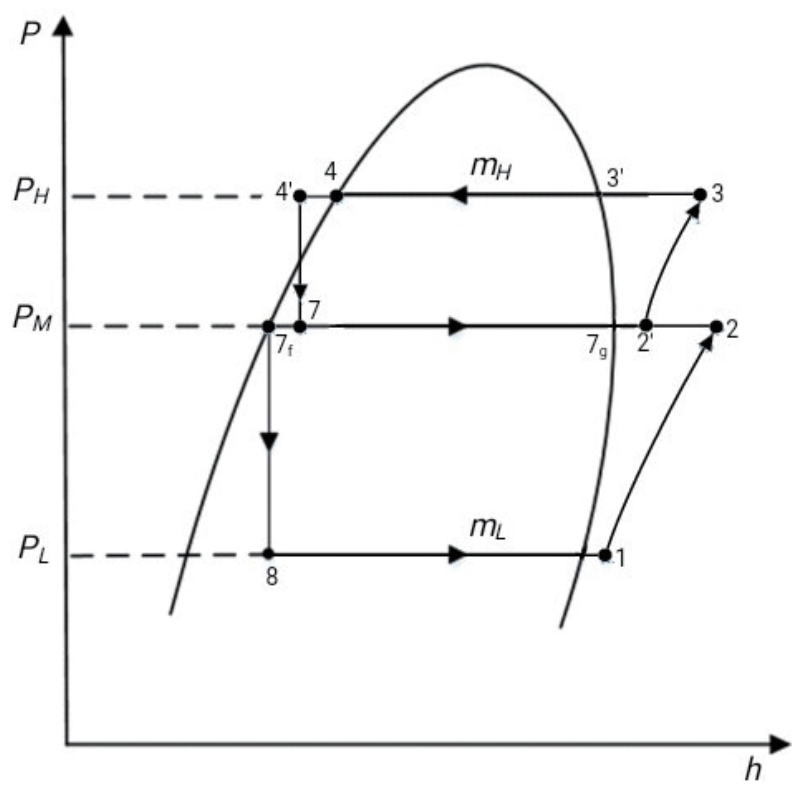

Fig. 3. Pressure-enthalpy diagram of the two-stage compression refrigeration with a flash tank. 
The refrigerant mass flow rates in the high-pressure circuit of the condenser and the primary circuit of the evaporator are $\dot{m}_{H}$ and $\dot{m}_{L}$, respectively. The saturated refrigerant stream from expansion valve 1 enters the flash tank, and two refrigerant streams flow out from the flash tank. Among the two streams, one stream is a saturated refrigerant liquid with a mass flow rate of $\dot{m}_{L}$ passing through expansion valve 2 then entering the evaporator. The other stream is a saturated refrigerant vapor with a mass flow rate of $\dot{m}_{H}-\dot{m}_{L}$ leaving the flash tank and mixing with the compressed refrigerant vapor from the first stage of the compressor.

The designed heating capacity and cooling capacity of the heat pump system are $\dot{Q}_{h}$ and $\dot{Q}_{\text {evap }}$, respectively, which can be expressed as

$$
\begin{gathered}
\dot{Q}_{h}=\dot{m}_{H} \cdot\left(h_{3}-h_{4}^{\prime}\right), \\
\dot{Q}_{\text {evap }}=\dot{m}_{L} \cdot\left(h_{1}-h_{8}\right) .
\end{gathered}
$$

From the energy conservation law of the heat pump system, the required compressing power $\left(W_{c}\right)$ for the heat pump system can be obtained from

$$
W_{c}=\dot{Q}_{h}-\dot{Q}_{\text {evap }}
$$

As shown in Fig. 3, the saturated refrigerant vapor from the flash tank (state point of $7 g$ ) mixed with the compressed refrigerant vapor from the first stage of compression (point 2) becomes a refrigerant vapor mixture (point 2'). The mixture is further compressed by the second stage of compression to a superheated vapor with a thermodynamic state corresponding to point 3. The enthalpy of the state corresponding to point 2' $\left(h_{2}^{\prime}\right)$ can be obtained from the energy conservation at point 2', i.e.,

$$
\dot{m}_{L} h_{2}+\left(\dot{m}_{H}-\dot{m}_{L}\right) h_{7 g}=\left(\dot{m}_{H}\right) \cdot h_{2}^{\prime}
$$

The average intermediate pressure from the flash tank, $P_{M}$, can be obtained from

$$
P_{M}=\sqrt{P_{H} P_{L}}
$$

where $P_{H}$ and $P_{L}$ are the condensation pressure and evaporation pressure of the refrigeration cycle, respectively.

The thermodynamic state of point 2' is obtained from the intermediate pressure of the vapor injection from Eq. (5) and the calculated $h_{2}^{\prime}$ value.

The total required compression power contains the powers for the first and second stages of compression, and can be expressed as

$$
W_{c}=\dot{m}_{L} \cdot\left(h_{2}-h_{1}\right)+\left(\dot{m}_{H}\right)\left(h_{3}-h_{2}^{\prime}\right) .
$$


Owing to the isentropic assumption in the compression process, the entropy of the state at point 3 is equal to that at point 2', i.e.,

$$
s_{3}=s_{2}^{\prime}
$$

The thermodynamic state at point 3 is obtained from the entropy of the state at point 3 and the given condensation pressure of the refrigeration cycle, $P_{H}$.

When the thermodynamic states of all points in Figs. 2 and 3 are known, the cooling capacity $\left(\dot{Q}_{\text {evap }}\right)$ and total required compression power $\left(W_{c}\right)$ can be obtained, and $\mathrm{COP}_{h}$ can be calculated from

$$
C O P_{h}=\dot{Q}_{h} / W_{c}
$$

However, in Fig. 3, the thermodynamic states of points 2' and 3 have to be determined from iterative calculations including a major iteration and a sub-iteration. In the iterative calculations, as shown in Fig. 4, first, the value for the refrigerant mass flow rate in the primary route $\left(\dot{m}_{L}\right)$ is estimated. From Eqs. (2) and (3), the total required power $\left(W_{c}\right)$ is calculated. Then, the enthalpy of state point 2' $\left(h_{2}^{\prime}\right)$ is estimated. From Eqs. (4) and (6), a new total required power $\left(W_{c}^{\prime}\right)$ is obtained. If the deviation between $W_{c}$ and $W_{c}^{\prime}$ exceeds the criterion value, then a new value for the enthalpy of state point 2' $\left(h_{2}^{\prime}\right)$ has to be guessed again, and the calculations in the sub-iteration must be performed again until the deviation is less than the criterion value. If the deviation of the two required power values is less than the criterion value, then the thermodynamic state of point 2' can be determined from $h_{2}^{\prime}$ and the intermediate pressure $P_{M}$ in the sub-iteration.

After the thermodynamic state of point 2' is determined in the sub-iteration, from the isentropic compression assumption $\left(s_{3}=s_{2}^{\prime}\right)$, the thermodynamic state of point 3 and the corresponding enthalpy $h_{3}$ can be obtained from the entropy of the state at point $3\left(s_{3}\right)$ and the given condensation pressure of the refrigeration cycle $\left(P_{H}\right)$. A new enthalpy of the state at point 3 is then obtained from Eq. (1). Comparing the two enthalpy values of $h_{3}$ from Eq. (1) and from the isentropic compression assumption, if the deviation of the two enthalpy values exceeds the criterion value, then another new value of the refrigerant mass flow rate in the primary route $\left(\dot{m}_{L}\right)$ has to be given and the sub-iteration must be performed again until the enthalpy deviation is less than the criterion value. If the enthalpy deviation is less than the criterion value, then the main iteration calculations are completed and $\mathrm{COP}_{h}$ of the heat pump system can be determined.

\section{Results and Discussion}

\subsection{Performance analysis of the heat pump upon adjusting the vapor injection pressure at different condensation temperatures}

To find the optimal openness of the two-way control valve in the vapor injection circuit and the corresponding vapor injection pressure for the best performance of the heat pump, a series 


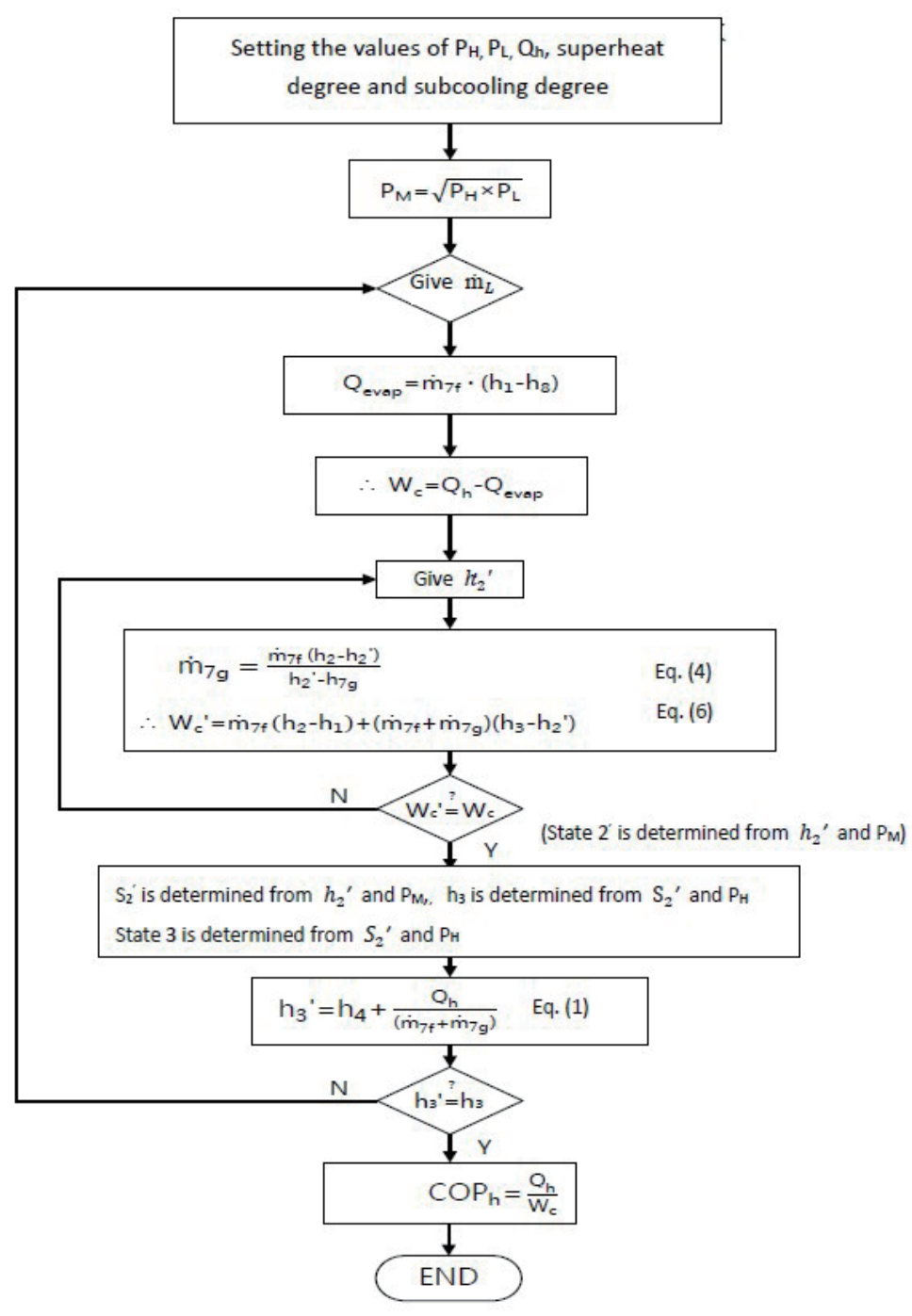

Fig. 4. Flow chart of theoretical analysis in the study.

of performance measurements in terms of $\mathrm{COP}_{h}, \mathrm{COP}_{c}$, and the required power consumption were performed by adjusting the openness of the two-way valve under different condensation temperatures. $\mathrm{COP}_{h}$ and $C O P_{c}$ can be obtained from Eq. (8) by directly sensing the flow rate of the circulation heating/chilled water, the circulating water temperature difference at the inlet and outlet of the condenser/evaporator, and the required power consumption of the system with a water flow meter, temperature sensors, and a power meter.

To attain the best heating performance of the heat pump system, the openness of the two-way valve during the vapor injection was adjusted to the optimal position at different condensation temperatures. Figure 5 shows the distributions of the optimal value of $\mathrm{COP}_{h}$, the corresponding value of $C O P_{c}$, and the required power of the heat pump system for different condensation temperatures. Under the optimal operational conditions, with increasing condensation temperature, the corresponding condensation pressure in the refrigeration cycle also increases. 


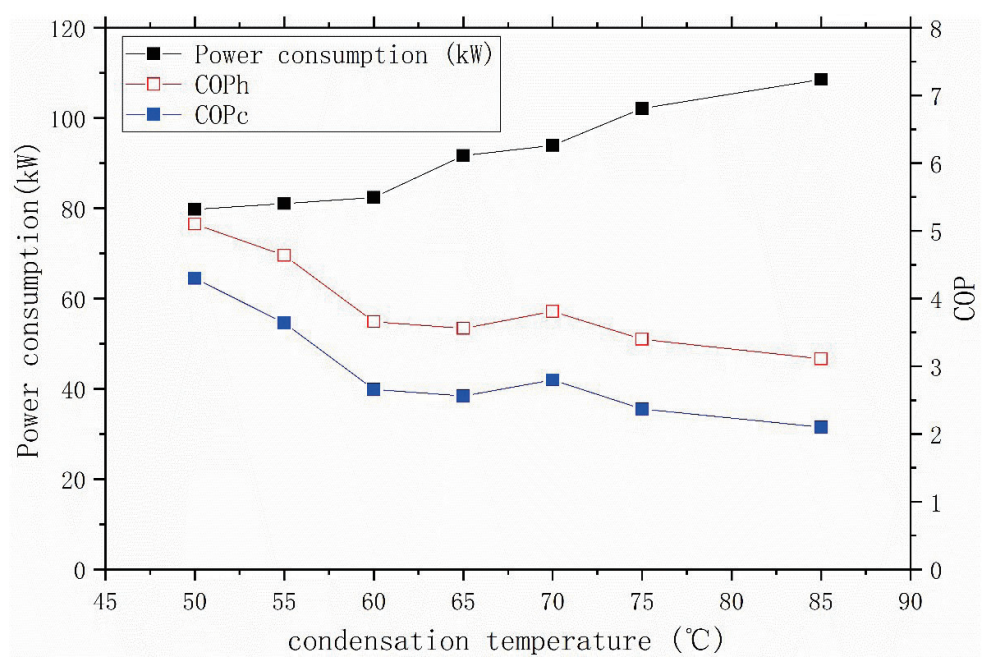

Fig. 5. (Color online) Optimal value of $\mathrm{COP}_{h}$, corresponding value of $\mathrm{COP}_{c}$, and required power of heat pump system at different condensation temperatures.

More power is necessary for the compressor to compress the superheated refrigerant vapor to a higher-pressure state at a higher condensation pressure. Thus, the required power of the heat pump system gradually increases with the condensation temperature. This phenomenon results in $\mathrm{COP}_{h}$ and $\mathrm{COP}_{c}$ gradually decreasing with increasing condensation temperature. From the figure, it can be seen that at the condensation temperature of $85^{\circ} \mathrm{C}, \mathrm{COP}_{h}$ is 3.2 in the optimal operation.

Figure 6 shows a comparison of the required powers and corresponding $\mathrm{COP}_{h}$ values at different condensation temperatures obtained by theoretical analysis and with optimal adjustment of the vapor injection method. In the figure, the trends of the results obtained by theoretical analysis and with optimal adjustment are similar. This indicates that the experimental accuracy in the study is reliable. However, owing to the energy loss and nonisentropic compression of the heat pump system, at the same condensation temperature, greater power will be required in actual operation, resulting in a lower $C O P_{h}$ of the heat pump system in actual operation. The deviations of the theoretical and experimental values of $\mathrm{COP}_{h}$ and the required power are in the ranges of $11-20 \%$ and $4-20 \%$, respectively. However, the deviations gradually decrease with increasing condensation temperature.

\subsection{Performance analysis of the heat pump system with automatic control for vapor injection in terms of condensation temperature}

On the basis of the optimal adjustments at different condensation temperatures, a regression equation is obtained in terms of the subcooling degree and condensation temperature by leastsquares approximation in order to further control the intermediate pressure of vapor injection to attain high heating performance of the system. The regression equation for the relationship between subcooling degree $(T s c)$ and condensation temperature $(T c)$ is 


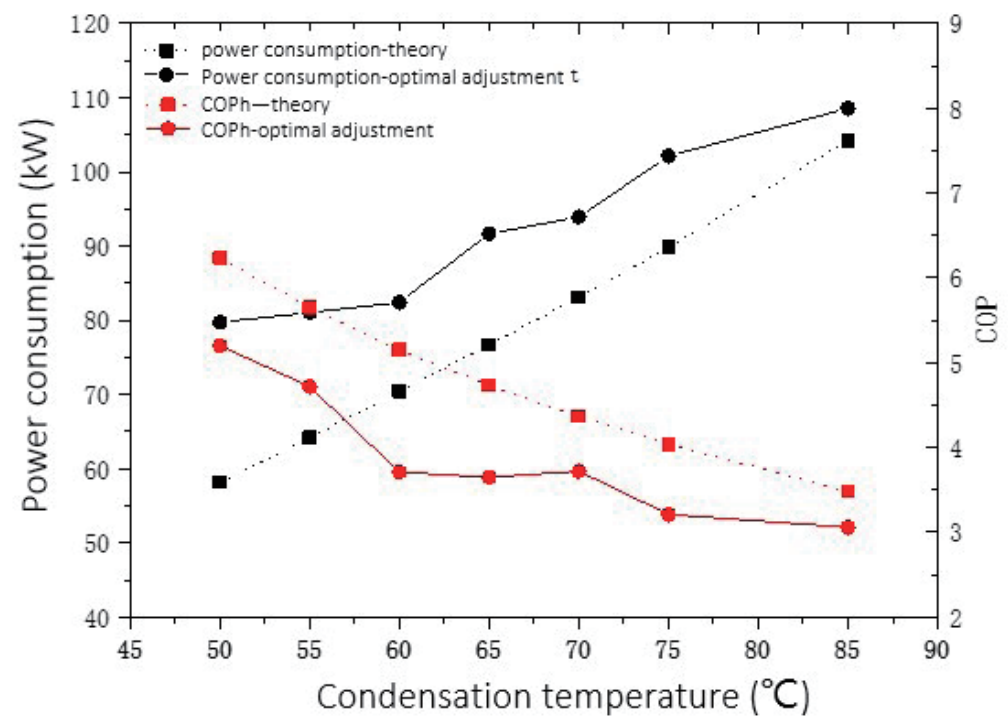

Fig. 6. (Color online) Comparison of required powers and $\mathrm{COP}_{h}$ of heat pump at different condensation temperatures obtained by theoretical analysis and with optimal adjustment.

$$
T s c=18.91922-0.53926 T c+0.0058 T c^{2} \text { with } R^{2}=0.97847 .
$$

Figure 7 shows a comparison of the heating capacities of the heat pump system with optimal adjustment and with automatic vapor injection control at different condensation temperatures. It can be seen that the heating capacity of the heat pump with optimal adjustment of the two-way valve is always greater than that with the automatic control method at the same condensation temperature, and is $14 \%$ greater on average. The distribution of the heating capacity of the heat pump in terms of the condensation temperature is similar with the two control methods.

Figure 7 also shows a comparison of the cooling capacities of the heat pump system with optimal adjustment and with automatic vapor injection control at different condensation temperatures. Similarly to the heating capacity, the cooling capacity of the heat pump with optimal adjustment is always greater than that with the automatic control method at the same condensation temperature, and is $16 \%$ greater on average. The distribution of the cooling capacity of the heat pump in terms of the condensation temperature is also similar with the two control methods. In the case with automatic control, the openness of the two-way valve in the vapor injection circuit is controlled in terms of the subcooling degree of the refrigeration cycle and the condensation temperature. Owing to the scale limit of the two-way valve openness, the subcooling degree of the refrigeration cycle cannot be exactly controlled to the value corresponding to the regression model at each condensation temperature. Thus, some deviations in the heating capacity and cooling capacity exist with the two control methods.

Regarding the required power for the heat pump in operation with increasing condensation temperature in Fig. 7, it can be seen that the required power with the two control methods gradually increases with the condensation temperature, and the difference in the required power with the two control methods is small. 


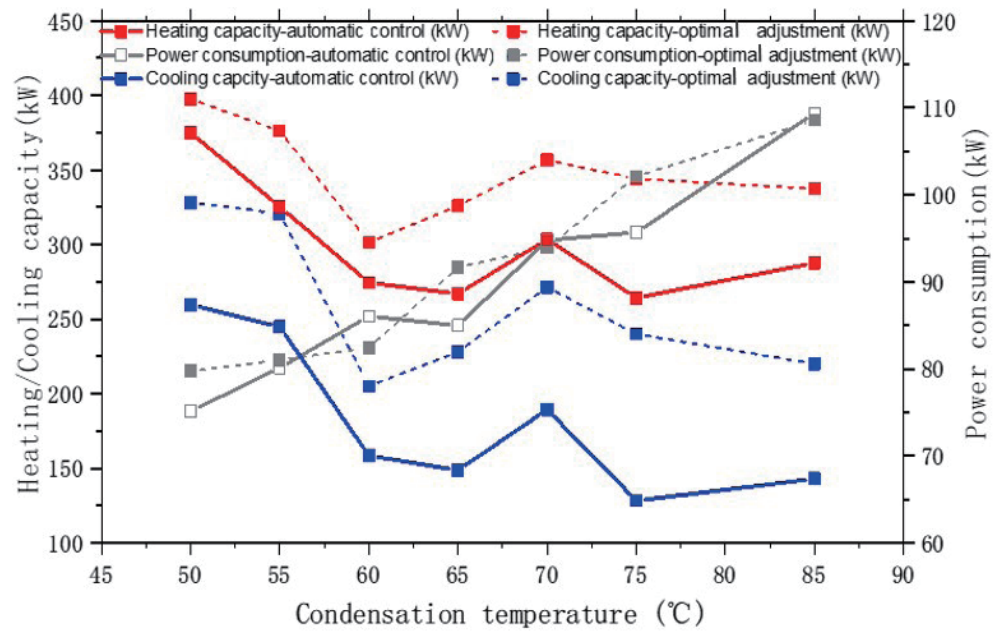

Fig. 7. (Color online) Comparison of heating/cooling capacities and power consumption of heat pump system with optimal adjustment and with automatic vapor injection control at different condensation temperatures.

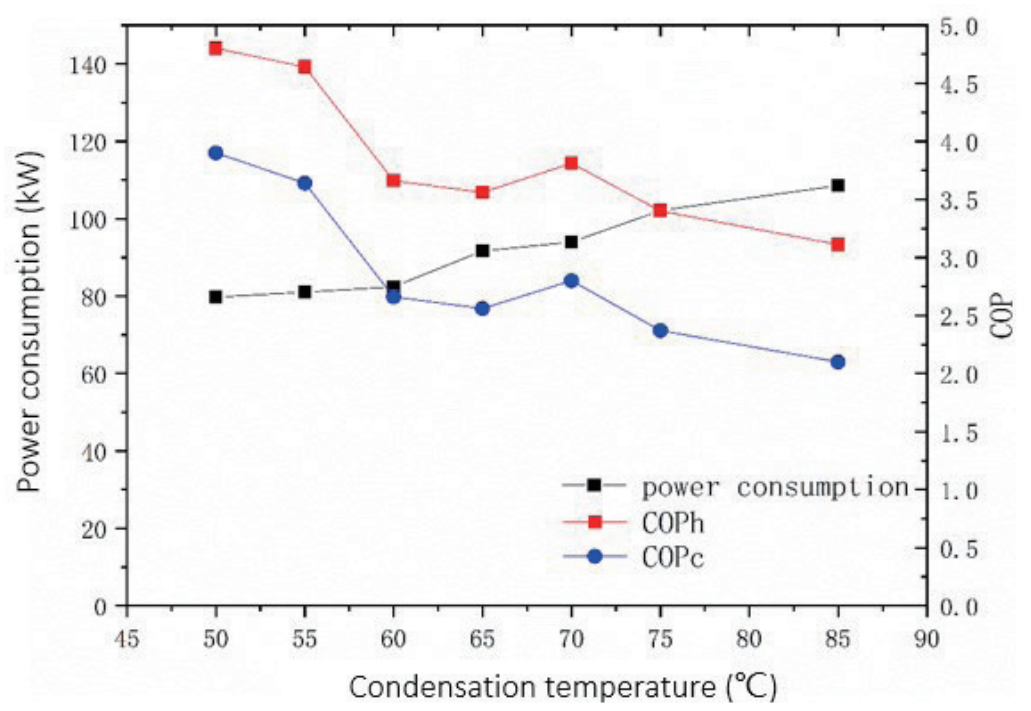

Fig. 8. (Color online) Overall performance of heat pump system with automatic vapor injection control.

Figure 8 illustrates the heating performance $\left(C O P_{h}\right)$, cooling performance $\left(C O P_{c}\right)$, and the required power of the heat pump with automatic control at different condensation temperatures. It can be seen that, owing to the increase in the power consumption of the heat pump with the condensation temperature, both $\mathrm{COP}_{h}$ and $\mathrm{COP}_{c}$ gradually decrease with increasing condensation temperature. For the automatic control method, $\mathrm{COP}_{h}$ of the heat pump reaches 3.1 at the high condensation temperature of $85^{\circ} \mathrm{C}$.

Figure 9 shows a comparison of the $\mathrm{COP}_{h}$ values of the heat pump with increasing condensation temperature with optimal adjustment, automatic control, and constant openness for the two-way valve. It can be seen that the difference between the $C O P_{h}$ values of the heat 
pump with optimal adjustment and automatic control is small, and the $C O P_{h}$ values with the control methods are on average $20 \%$ greater than those when the two-way valve has constant openness.

Figure 10 shows a comparison of $\mathrm{COP}_{h}$ and the required power of the heat pump at different condensation temperatures with automatic control and the values obtained by theoretical analysis. The $\mathrm{COP}_{h}$ values of the heat pump obtained by theoretical analysis are always greater than those with optimal control at the same condensation temperature owing to the isentropic compression assumption of the theoretical analysis, which ignores the pressure drop in the refrigeration cycle. The difference in the $C O P_{h}$ values is in the range of $12.5-24 \%$ and gradually decreases with increasing condensation temperature.

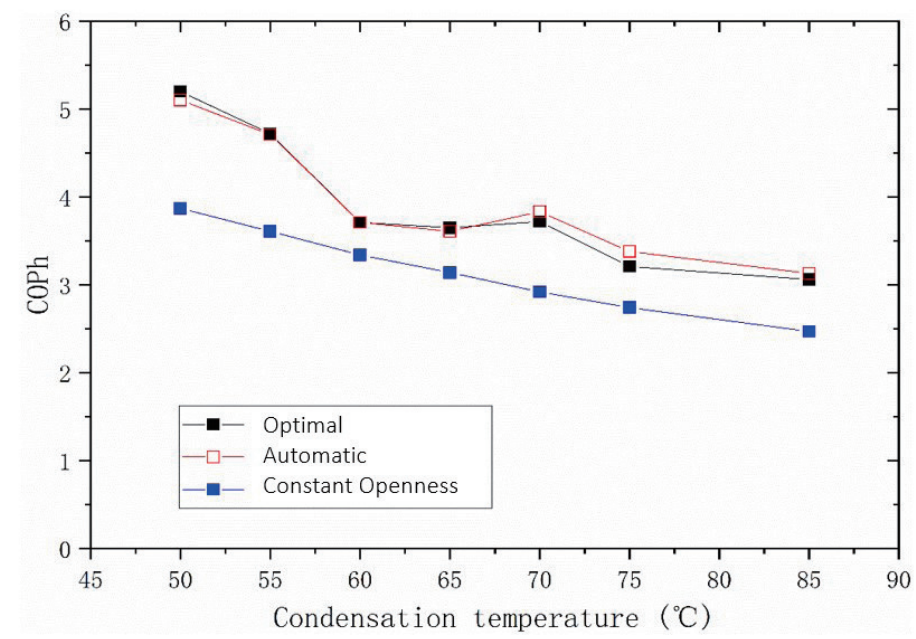

Fig. 9. (Color online) Comparison of $\mathrm{COP}_{h}$ values of heat pump with optimal adjustment, automatic control, and constant openness for two-way valve at different condensation temperatures.

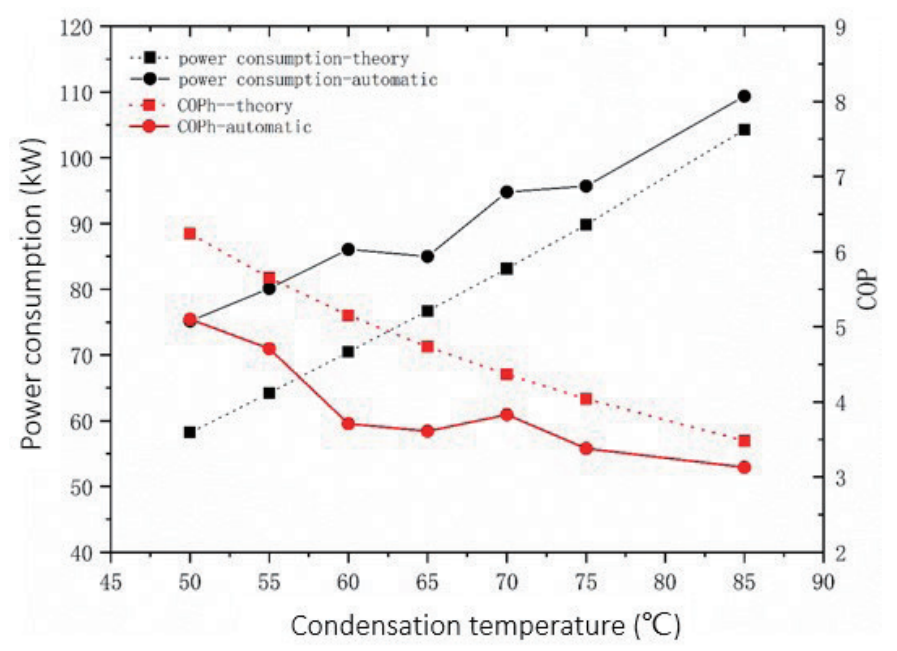

Fig. 10. (Color online) Comparison of required power consumption and $\mathrm{COP}_{h}$ obtained by theoretical analysis and with automatic vapor injection control. 


\section{Conclusions}

For a high-temperature heat pump system during the water heating process, owing to the dynamical variations in the water heating and condensation temperatures, the automatic and optimal control of the heat pump system in operation cannot be implemented through the traditional feedback control method by directly sensing the vapor injection pressure of the refrigeration cycle. In this study, we first adjusted the openness of the vapor injection valve to find the suitable vapor injection pressure for each condensation temperature for the optimal operation of the system. It was found that, for the optimal performance of the developed system in dynamical operation, the vapor injection pressure of the heat pump at each condensation temperature is related to the corresponding subcooling degree. The subcooling degree of the refrigeration cycle was obtained from the temperature sensors in the condenser and at the refrigerant inlet of the expansion valve. Then, a regression model was built in order to control the intermediate vapor injection pressure of a two-stage compression heat pump system in terms of the subcooling degree and the condensation temperature of the refrigeration cycle. By sensing the condensation temperature of the refrigeration cycle, the corresponding subcooling degree of the refrigeration cycle for the optimal vapor injection pressure can be determined from the regression model. Then, the openness of the control valve on the vapor injection piping route is automatically adjusted to approach the corresponding optimal subcooling degrees of different condensation temperatures to attain high operational performance.

The operational performance of the heat pump system with automatic control of vapor injection was compared with those with optimal adjustment of vapor injection and the results of theoretical analysis. Owing to the isentropic assumption and ignoring the pressure drops in the refrigeration cycle in theoretical analysis, the experimental results are in agreement with the theoretical results within a range of $10-20 \%$. In comparison with the system with constant vapor injection pressure, $\mathrm{COP}_{h}$ of the system can be increased by $20 \%$ on average by vapor injection pressure control. From the experimental results, it is found that $\mathrm{COP}_{h}$ and the required power of the heat pump system for the proposed automatic control method are in reasonable agreement with those obtained by optimal adjustment at different condensation temperatures. This indicates that the proposed model of automatic vapor injection can be applied to dynamically control the intermediate pressure of the refrigeration cycle to maintain high operational performance of a two-stage compression heat pump.

\section{Acknowledgments}

The authors gratefully acknowledge the financial support provided to this study by the Ministry of Science and Technology of Taiwan under Grant No. MOST 106-2622-E-167-006CC3.

\section{References}

1 W. J. Luo, D. Faridah, F. R. Fasya, Y. S. Chen, F. H. Mulki, and U. N. Adilah: Energies 12 (2019) 3470. https:// doi.org/10.3390/en12183470 
2 C. C. Chang, W. J. Luo, C. W. Lu, Y. S. Cheng, B. Y. Tsai, and Z. H, Lin: Sci. Technol. Built Environ. 23 (2017) 81. https://doi.org/10.1080/23744731.2016.1210971

3 K. Y. Li, W. J. Luo, B. Y. Tsai, and Yean-Der Kuan: Sustainability 12 (2020) 7357. https://doi.org/10.3390/ su12187357

4 W. J. Luo, K. Y. Li, J. M. Huang, and C. K. Yu: Energies 13 (2020) 4896. https://doi.org/10.3390/en13184896

5 X. Wang, J. Yu, and M. Xing: Energy Convers. Manage. 100 (2015) 242. https://doi.org/10.1016/ j.enconman.2015.05.017

6 S. Jiang, S. Wang, X. Jin, and T. Zhang: Int. J. Refrig. 51 (2015) 88. https://doi.org/10.1016/j.ijrefrig.2014.12.005

7 C. Baek, J. Heo, J. Jung, H. Cho, and Y. Kim: Energy 77 (2014) 570. https://doi.org/10.1016/j.energy.2014.09.038

8 H. Qiao, V. Aute, and R. Radermacher: Int. J. Refrig. 84 (2017) 181. https://doi.org/10.1016/j.ijrefrig.2017.08.020

9 X. Jin, S. Wang, and M. Huo: 1st Int. Conf. Building Energy and Environment (2008) 1437.

10 A. Redón, E. Navarro-Peris, M. Pitarch, J. Gonzálvez-Macia, and J. M. Corberán: Appl. Energy 124 (2014) 231. https://doi.org/10.1016/j.apenergy.2014.02.066

11 Y. He, F. Cao, L. Jin, X. Wang, and Z. Xing: Int. J. Refrig. 60 (2015) 1. https://doi.org/10.1016/j.ijrefrig.2015.08.012

12 D. Lee, K. J. Seong, and J. Lee: Int. J. Refrig. 50 (2015) 115. https://doi.org/10.1016/j.ijrefrig.2015.01.013

13 F. M. T. Oquendo, E. N. Peris, J. G. Macia, and J. M. Corberán: Int. J. Refrig. 63 (2016) 144. https://doi. org/10.1016/j.jijrefrig.2015.10.035

14 J. Jung, Y. Jeon, H. Lee, and Y. Kim: Appl. Therm. Eng. 127 (2017) 800. https://doi.org/10.1016/ j.applthermaleng.2017.08.098

15 X. Xu, Y. Hwang, and R. Radermacher: Int. J. Refrig. 34 (2011) 402. https://doi.org/10.1016/j.ijrefrig.2010.09.015

16 X. Xu, Y. Hwang, and R. Radermacher: Int. J. Refrig. 34 (2011) 1922. https://doi.org/10.1016/j.ijrefrig.2011.08.003

17 C. W. Roh, and M. S. Kim: Int. J. Refrig. 34 (2011) 1911. https://doi.org/10.1016/j.ijrefrig.2011.07.011

18 S. Jiang, S. Wang, X. Jin, and Y Yu: Int. J. Refrig. 70 (2016) 57. https://doi.org/10.1016/j.ijrefrig.2016.06.024

19 W. J. Luo, J. C. Lai, P. Y. Hsieh, and F. R. Fasya: Sens. Mater. 30 (2018) 2599. https://doi.org/10.18494/ SAM.2018.2070

20 J. C. Lai, W. J. Luo, J. Y. Wu, D. Faridah, C. M. Lin, F. R. Fasya, M. Nuriyadi, and W. B. Ng: Adv. Mech. Eng. 10 (2018) 1. https://doi.org/10.1177/1687814018767487

\section{About the Authors}

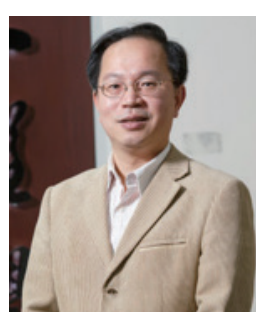

Win-Jet Luo earned his master's degree in engineering in 1994 and his Ph.D. degree in engineering in 2000 from National Chen Kung University (NCKU), Taiwan. At present, he is a professor in the Graduate Institute of Precision Manufacturing at National Chin-Yi University of Technology (NCUT). Since 2013, Prof. Luo has received the Distinguished Professor Award annually. His research has mainly focused on computational fluid dynamics, microelectromechanical systems, ventilation, energy saving, fuel cells, and microsensors. He has published more than 70 research papers in prestigious international journals, and as a result of his outstanding research, he has been invited to serve as a reviewer for journals. (wjluo@ncut.edu.tw)

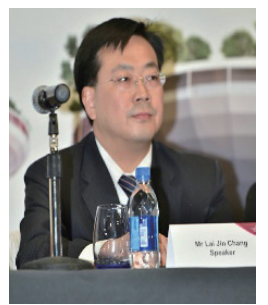

Jin-Chang Lai earned his master's degree from the Department of Energy and Refrigerating Air-Conditioning Engineering in 2004 and his Ph.D. degree from the Graduate Institute of Precision Manufacturing, National Chin-Yi University of Technology (NCUT), in 2020. His research interests are in heat pumps and high-efficiency chillers. (jclai@ncut.edu.tw) 


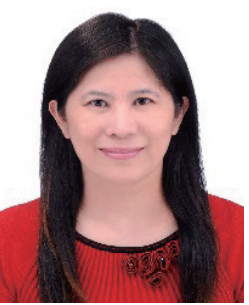

Ming-Chu Hsieh earned her Ph.D. degree in engineering in 2013 from National Taiwan University of Science and Technology, Taiwan. She is an associate professor in the Department of Mechanical Engineering, National Chin-Yi University of Technology (NCUT). Her research has mainly focused on computer-aided design. (smj@ncut.edu.tw)

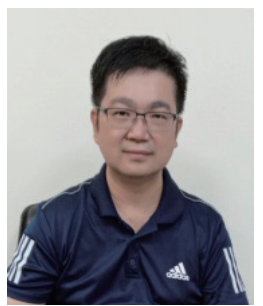

I-Hsing Huang earned his master's degree in 2000 and his Ph.D. degree in 2009, both from the Department of Electrical Engineering, National Chen Kung University (NCKU), Taiwan. His research interests include singlechip control and embedded system applications, energy-saving control of refrigeration and air conditioning, and power electronics.

(pestem@ncut.edu.tw) 